Preprints of the

Max Planck Institute for

Research on Collective Goods

Bonn 2010/36

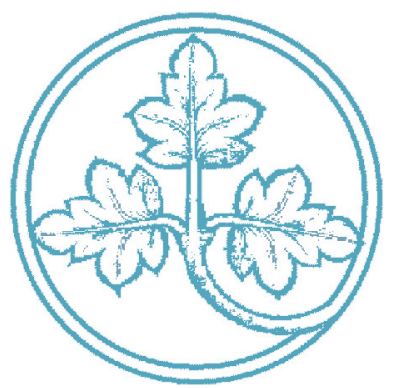

Information Disclosure,

Intertemporal Risk Sharing, and Asset Prices

Tri Vi Dang

Hendrik Hakenes

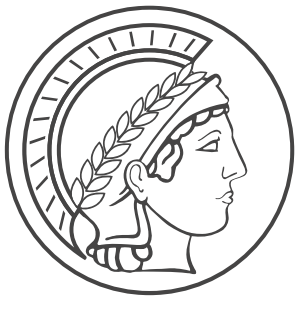




\title{
Information Disclosure, Intertemporal Risk Sharing, and Asset Prices
}

\author{
Tri Vi Dang / Hendrik Hakenes
}

September 2010 


\title{
Information Disclosure, Intertemporal Risk Sharing, and Asset Prices*
}

\author{
Tri Vi Dang ${ }^{\dagger}$ \\ Yale University and University of Mannheim \\ Hendrik Hakenes ${ }^{\ddagger}$ \\ Leibniz University Hannover and Max Planck Institute Bonn
}

September 2, 2010

\begin{abstract}
Disclosure of information triggers immediate price movements, but it mitigates price movements at a later date, when the information would otherwise have become public. Consequently, disclosure shifts risk from later cohorts of investors to earlier cohorts. Hence, disclosure policy can be interpreted as a tool to "control" interim asset price movements, and to allocate risk intertemporally. This paper shows that a policy of partial disclosure (and, hence, of intertemporal risk sharing) can maximize, but surprisingly also minimize, the market value of the firm. Our model also applies to a setting where a central bank chooses the quality and frequency of the disclosure of macroeconomic information, or to the precision of disclosure by (distressed) banks.
\end{abstract}

Keywords: Financial reporting, disclosure, information policy, asset pricing, intertemporal risk sharing, general equilibrium.

JEL-Classification: D92, G14, M41.

*We would like to thank Dirk Bergemann, Eddie Dekel, Darrell Duffie, Christoph Engel, Gary Gorton, Kristoffel Grechenig, Martin Hellwig, Jos Jansen, Ken Judd, Johannes Hörner, Felix Kübler, Dilip Madan, Larry Samuelson, Ulf Schiller, Matthew Spiegel, Elu von Thadden, and seminar participants in Hannover, Augsburg, Leipzig, Eltville, at the German Economic Association and at the GEABA for helpful comments. All errors remain our own.

†Yale University, Department of Economics, 30 Hillhouse Avenue, New Haven, CT 065208281. trivi.dang@yale.edu

$\ddagger$ Institute of Financial Economics, Leibniz University Hannover, Königsworther Platz 1, 30167 Hannover, Germany. hakenes@fmt.uni-hannover.de. 


\section{Introduction}

The discussion about the optimal degree of disclosure is old but still controversial. The recent debate, whether the U.S. Federal Reserve Bank and the European Central Bank should announce the results of bank stress tests, attracted much public attention. Another example is the ongoing discussion about the costs and benefits of providing earnings guidance by public companies. After Congress passed the Safe Harbor law that protected companies from legal liability in performance forecasts, the practice of providing forward-looking information, such as earnings per share guidance, became routine during the late 1990s. The number of firms providing guidance increased from 92 in 1994 to approximately 1,200 in $2001 .^{1}$

These two types of disclosure, the disclosure of information about the ability of a bank to manage a change in the future macroeconomic environment and the firm's voluntary forecast of next quarter's earnings and sales, have one thing in common. They may trigger immediate price movements, but they mitigate price movements at a later date, when the information would otherwise have become public. Consequently, disclosure shifts the "timing" of price changes and thus risk from later cohorts of investors to earlier cohorts. ${ }^{2}$

In this paper we analyze whether and how the mere decision to release of future interim information with no impact on the distribution of cash flows can change today's market value of the firm. In the central bank example, the interim information is the result of a stress test. How does the central bank's decision to release stress test information in the future affect prices today? In the case of earnings guidance, how does a firm's decision to change the policy of providing earnings guidance affect the market value of the firm? As the basic idea of the paper, information influences market prices, hence potential information is equivalent to price risk. But all information is revealed sooner or later. Consequently, an information disclosure policy can be seen as a mechanism to control the timing of price changes and intertemporally allocate price risk.

Our paper focuses on the following two interrelated questions. First, how does the release of interim information affect interim asset price movements, and thus intertemporal risk sharing among investors? Second, how does intertemporal risk sharing among different investors affect the risk premia they

\footnotetext{
${ }^{1}$ See Thomson Financial, April 2006, "Trends in Earnings Guidance," or The Economist, April 2006, "Decline of Earnings Guidance."

${ }^{2}$ In a survey, $46 \%$ of companies that provide earnings guidance said that they do so in order to try to limit stock volatility. See Deloitte Financial Executives Research Foundation, June 2009, Earnings Guidance: The Current State of the Play.
} 
demand, and thus ex ante asset prices? The paper discusses which disclosure policy maximizes a firm's market value, which policies are preferred by different investors, and which policy is welfare-optimal.

Conventional wisdom may suggest that the announcement of a future announcement is irrelevant for today's market price (see Ross, 1989) or maximizes the market value (see Epstein and Turnbull, 1980; Duffie, Schroder, and Skiadas, 1996, 1997). ${ }^{3}$ The main result of the present paper is to show that intertemporal risk sharing through the release of partial interim information can actually minimize the market value of the firm if the distribution of final cash flows exhibits a negative skewness, low variation, and if investors are not too risk averse. In such a case, the optimal disclosure policy of the firm is no interim financial reporting or no earnings guidance.

In this paper we consider an economy with three dates and three types of agents. ${ }^{4}$ At date 0, all agents have identical information about the exogenous cash flow distribution of the firm. The firm's cash flow is realized and publicly known at date 2. At date 0, the entrepreneur sells the whole firm to riskaverse early (first-cohort) investors for the price $P_{0}$ and consumes the proceeds. At date 1, early investors want to consume and sell their shares to equally risk-averse late (second-cohort) investors for a price $P_{1}$. At date 2 , the cash flow is realized and late investors consume. Asset prices are determined in a competitive market. At any date, there is symmetric information between agents who trade with each other.

As mentioned above, for a given cash flow process, an interim disclosure policy can be used as a mechanism to control interim price movements (i. e., the set of possible prices $P_{1}$ at date 1 ), and fine-tune multi-period risk sharing among investors, which affects the risk premia that different cohorts of investors demand, and thus the market value of the firm. If no interim information is released, then early investors face no risk at all, and late investors bear the full risk. If vice versa perfect information is released in date 0.5, then early investors bear all the risk.

We show that intertemporal risk sharing through the release of partial interim information can actually minimize the market value of the firm if the distribution of final cash flows exhibits a negative skewness, low variation, and if investors are not too risk averse. Intuitively, for a value-minimizing disclosure policy, the "sum" of the risk premia the two cohorts of investors demand is higher than the risk premium that one cohort of investors demands when

\footnotetext{
${ }^{3}$ We thoroughly relate our paper to the literature in the next section.

${ }^{4}$ In order to highlight the interplay between the disclosure of interim information, interim price movements, intertemporal risk sharing, and asset pricing, this paper frames the analysis within a financial reporting context.
} 
it bears all the risk. Because of investors' risk aversion, the firm's market value is influenced relatively little by large potential upward price movements. Hence, the firm chooses a disclosure policy that avoids pronounced upward movements.

If interim disclosure increases firm value, then firms will implement a policy of partial disclosure. We can hence deduce empirical predictions. Innovative firms (right skewness of the cash flow distribution) should commit to release more information, especially if investors are rather risk averse (or ownership is concentrated), or if the dispersion of cash flows is large. In each of these cases, the potential value increase is large, hence the firm must choose partial disclosure in order not to attain the complete value increase at one go. Otherwise, due to investors' risk aversion, this value increase would turn out small.

This paper also analyzes the preferences of the two investor cohorts for disclosure of interim information. In a competitive market, investors earn rents for bearing risk. Analogous to the standard demand and supply model, the more risk the investor has to bear, the higher the rents, i. e., the area between demand (marginal willingness to pay) and price curve becomes larger. Although investors are risk averse, they like bearing risk ex ante since bearing risk in a competitive financial market means earning higher rents. Consequently, early investors prefer full interim disclosure at date 0.5, while late investors want the firm not to disclose any interim information.

The potential divergence of interests becomes evident in a case that has attracted much public attention: the dispute between Deutsche Boerse AG and Porsche AG concerning quarterly reports. After Porsche had refuted to switch from half-year reporting to quarterly reporting, Deutsche Boerse removed the carmaker from the German midcap MDAX index. The chronology of this controversial debate is summarized in appendix B, highlighting different types of conflicts of interests as well as several crucial issues regarding the costs and benefits of more frequent and more precise earnings reporting by firms.

Our analysis is framed within a financial reporting setting, but the mechanism, the intuitions, and the implications are relevant whenever intertemporal risk sharing is an issue. For example, one can analyze the optimal precision and timing of rating changes, both from the viewpoint of rating agencies and investors. Similarly, central bank or treasury department may decide on how often to release interim macroeconomic information, such as inflation rates, unemployment rates, or growth forecasts. The release of macroeconomic information typically triggers price movements at the announcement day. Potential price movements affect intertemporal risk sharing between different investor cohorts and thus the market risk premia they demand. Since investors are rational and forward looking, the anticipation of potential interim price movements affect the ex ante market value of the aggregate stock market. Similar 
questions arise. How does a given disclosure policy of the central bank affect the allocation of systematic risk that different cohorts of investors (current investors and future investors) have to bear? How are current and future market prices affected? And what is the optimal disclosure policy in order to to maximize the joint payoffs to different investors cohorts?

The rest of the paper is organized as follows. The next section relates this paper to the literature. Section 3 introduces the model. Then in Section 4, the competitive equilibrium is discussed, first for a one-period model, then for the two-period model. Section 5 discusses some applications, and derives testable hypotheses. Section 6 gives a welfare analysis and discusses the interests of the cohorts of investors. Section 7 concludes. All proofs are in the appendix, and so is the time line of the Porsche case.

\section{Relation to the Literature}

The literature on information disclosure in financial markets is large and multifaceted. In a seminal paper, Ross (1989) employs the no-arbitrage martingale approach and establishes a Resolution Irrelevancy Theorem which states that, in an arbitrage-free economy, a mere change of the timing of the uncertainty resolution cannot change current prices, unless the cash flow distribution is altered. Epstein and Turnbull (1980) show that in a setting where investors trade and consume in multi-periods, the disclosure of interim information allows for better consumption and trading choices. They show that partial disclosure always maximizes the ex ante market value of the firm. Duffie, Schroder, and Skiadas $(1996,1997)$ analyze the implications of disclosure of interim information when traders have recursive utilities, and show that noisy disclosure always maximizes the ex ante market value.

In contrast to these papers where interim information disclosure is either irrelevant or always maximizes the value of the firm, we show that the disclosure of partial interim information may actually minimize the ex ante market value of the firm despite intertemporal risk sharing. Furthermore, this paper give conditions when a prescribe disclosure policy of interim information minimizes and maximizes the ex ante market value of the firm and when it is irrelevant.

The reason for these different results is the following. Ross (1989), Epstein and Turnbull (1980), and Duffie, Schroder, and Skiadas (1996, 1997), assume long-lived investors, while this paper assumes that some investors leave the market so that they only care about prices in some sub-periods of the whole trading setting. A motivation for this type of overlapping generation model structure is liquidity shocks put forward by Diamond and Dybvig (1983), or many market microstructure models. Some investors exhibit interim liquidity 
shocks and have to sell their asset holding. In such a setting, the expected release of information may depress stock prices because investors anticipate they may be forced to sell after a negative announcement.

A second story the heterogeneity of investors' trading horizons goes as follows. In the real world, portfolio managers are typically offered relatively high powered incentives schemes, and their performance is evaluated relatively frequently, which induces a kind of endogenous short horizon trading behavior. In contrast to Epstein and Turnbull (1980) and Duffie and Manso (2007), the present paper assumes heterogeneous investors along the time dimension, and is thus able to discuss potential conflicts of interests between investor cohorts. In their papers, all investors have the same preference for interim disclosure policy. Therefore, this paper may provide some intuitions for understanding the controversial debate between Porsche and Frankfurt Stock Exchange and the various types of conflicts of interests.

There is also a huge accounting literature on financial reporting (for a survey see Verrechia, 2001). A main focus of this literature is that financial reporting may serve as a tool to mitigate and resolve agency problems due to asymmetric information. In contrast, the present paper abstracts away from any type of agency problems and analyzes financial reporting as a tool to control interim price movements and intertemporal risk sharing so as to maximize the ex ante value of the firm. As pointed out, the mechanism, intuitions and implications this paper discusses also applies to information release and intertemporal risk sharing in a macroeconomic environment. In particular, the release of macroeconomic information represents systematic risk and has a first order effect on market pricing.

In our model, investors invest only for one period. In this respect, our model resembles the work of Spiegel (1998), or more recently Watanabe (2008); Sagi, Spiegel, and Watanabe (2009); Biais, Bossaerts, and Spatt (2010). There is also a recent literature on endogenous short investment horizons of funds managers. This literature shows that financial contracting may induce rational managers to behave like myopic agents. They only care about the next period payoffs or fiscal or even quarterly trading performances. The Porsche case showed that, in addition to the Deutsche Börse, it was some institutional investors who propagated for changes of Porsche's disclosure policy. The trading setting of the present paper is similar to Allen, Morris, and Shin (2006). Other papers on financial markets with myopic traders are Tirole (1982) and Cespa and Vives (2008). In Shin (2006), managers and investors have asymmetric information. 


\section{The Basic Model}

Consider an entrepreneur (initial owner) who wants to sell his firm at date $t=0$. The firm's only asset is a project that matures in $t=2$ and yields $Y_{H}$ with probability $q$, otherwise it yields $Y_{L}<Y_{H}$.

There is a continuum of risk-averse investors, each endowed with $w$ units of a homogenous consumption-investment good. A first cohort (early investors) of mass 1 lives from period 0 to period 1, another cohort (late investors) of mass one lives from 1 to 2 . As a consequence, an early investor who buys a share of the firm at date $t=0$ will have to sell it at $t=1$, without directly profiting from the yields. A late investor who buys the share at $t=1$ can then wait until $t=2$ for the firm's yield. In order to abstract from wealth effects of investors, let us assume that investors exhibit constant absolute risk aversion, hence $u(c)=-e^{-\rho c}$. As an alternative to the risky asset, investors can invest into a risk-free asset at rate $r$. The stock market is competitive. The timing of the model is given in figure 1 .

Figure 1: Timing of the Model

0 An initial owner commits to a disclosure policy $\theta$, then sells shares on a competitive market to early investors.

$\frac{1}{2}$ The firm learns the outcome $Y$, releases a (possibly noisy) signal about $Y$ with precision $\theta$.

1 Early investors sell their shares to late investors on a competitive market; then they consume.

2 Late investors receive the payment $Y$ from the firm; then they consume.

The initial owner tries to maximize firm value by implementing a disclosure policy $\theta$. Here, $\theta$ is the precision of a signal $s \in\{L, H\}$ on final output $Y \in\left\{Y_{L}, Y_{H}\right\}$, disclosed before the market between early and late investors takes place. To be concrete, $\operatorname{Pr}\left\{s=H \mid Y=Y_{H}\right\}=(\theta+1) / 2$ and $\operatorname{Pr}\{s=$ $\left.L \mid Y=Y_{L}\right\}=(\theta+1) / 2$. Consequently, there is perfect disclosure for $\theta=1$, and zero disclosure for $\theta=0$. The signal $s$ can be seen as a garbling of the original information (see e. g. Baglioni and Cherubini, 2007; Weber and Croson, 2004). Trade will be influenced by the signal; a good signal will lead to a price increase, and the price reaction will be larger if the signal is rather precise. The initial price $P_{0}$ cannot depend on the signal $s$ itself, but it may depend on the signal's precision $\theta$. The initial owner is assumed to install a policy $\theta$ that maximizes $P_{0}$. 
Since the focus is on the implications of disclosure of interim information for interim price movements, intertemporal risk sharing, and ex ante asset pricing, this paper abstracts away from any type of agency problems due to asymmetric information. Therefore, this paper assumes that the cash flow distribution is common knowledge at date 0 , and the entrepreneur sells the whole firm at date 0 , so that his commitment to announce the pre-specified interim information is credible. At any dates, there is symmetric information between agents who trade with each other. Similarly, if the firm does not receive perfect interim information, this will only make the updating slightly more complicated but does not alter the main qualitative results of the paper.

\section{Equilibrium}

Let us first solve the model with only one generation of investors. The case of two generations and an interim signal will then be a straightforward generalization of these first results.

\subsection{The One-Period Case}

Consider the market for an asset that pays $Y_{H}$ with probability $q$, and otherwise $Y_{L}$. At a market price $P$, the expected utility for an investor who buys $\alpha$ units of the asset is

$$
\begin{aligned}
u(P, \alpha) & =q u\left[(1+r)(w-\alpha P)+\alpha Y_{H}\right]+(1-q) u\left[(1+r)(w-\alpha P)+\alpha Y_{L}\right] \\
& =-q e^{-(1+r)(w-\alpha P)-\alpha Y_{H}}-(1-q) e^{-(1+r)(w-\alpha P)-\alpha Y_{L}} .
\end{aligned}
$$

In equilibrium, investors must be indifferent with respect to buying an additional marginal share, $\partial u(P, \alpha) / \partial \alpha=0$. Furthermore, the market must clear;

the entire shares must be distributed between investors. Because all investors are identical, a representative investor must hold one share in equilibrium. As a consequence, $\partial u(P, \alpha) / \partial \alpha=0$ for $\alpha=1$,

$$
\begin{aligned}
\left.\frac{\partial u(P, \alpha)}{\partial \alpha}\right|_{\alpha=1} & =-e^{-\rho(1+r) w}\left[q e^{-\rho\left(Y_{H}-(1+r) P\right)} \rho\left(Y_{H}-(1+r) P\right)\right. \\
& \left.+(1-q) e^{-\rho\left(Y_{L}-(1+r) P\right)} \rho\left(Y_{L}-(1+r) P\right)\right]=0, \\
P & =\frac{1}{1+r} \frac{q Y_{H} e^{-\rho Y_{H}}+(1-q) Y_{L} e^{-\rho Y_{L}}}{q e^{-\rho Y_{H}}+(1-q) e^{-\rho Y_{L}}}
\end{aligned}
$$

The market is free of arbitrage; the good event has the risk neutral probability

$$
\frac{(1+r) P-Y_{L}}{Y_{H}-Y_{L}}=\frac{q e^{\rho Y_{L}}}{q e^{\rho Y_{L}}+(1-q) e^{\rho Y_{H}}},
$$


depending on $\rho, Y_{H}$ and $Y_{L}$. If risk aversion is large, $P=Y_{L}$, hence only the bad outcome $Y_{L}$ is taken into account because $e^{\rho Y_{H}} \gg e^{\rho Y_{L}}$. If risk aversion is low, then $P \approx q Y_{H}+(1-q) Y_{L}$ equals the expected value. Given that (2) is central to our model, let us discuss some elementary properties.

Lemma 1 Ceteris paribus,

- a higher interest rate $r$ decreases the price $P$,

- a higher success probability $q$ increases the price $P$,

- a higher risk aversion $\rho$ decreases the price $P$,

- a higher low yield $Y_{L}$ increases the price $P$,

- a higher high yield $Y_{H}$ increases the price $P$ up to some maximum.

The first four properties are not surprising. However, the fifth item states that the market price $P$ does not increase monotonically with the good-state return $Y_{H}$. In other words, the asset market does not honor large potential increases in value. ${ }^{5}$ The reason is simply that not the actual expected utility from a share, but its marginal expected utility determines the market price of an asset. The marginal utility from a payment $Y_{H}$ decreases as $Y_{H}$ increases. Consequently, the market price may even decrease as $Y_{H}$ increases. Let us thus stress that the benefit of initial owners from large potential price increases is limited.

This property will later help to understand why the optimal disclosure strategy may be noisy. If the signal is precise (or extremely imprecise), too much information is revealed at a single date. The ensuing value increase is not honored by the market, such that the initial owner does not fully benefit.

The interest rate $r$ appears only as a discount factor $1 /(1+r)$, hence it cannot influence the optimal disclosure policy. As a result, we can set $r:=0$ without loss of generality in the following.

\footnotetext{
${ }^{5}$ This property is not a consequence of exponential utility, it holds for more general types of utility functions, such as CRRA functions. We show this at the end of the proof of lemma 1. Of course, it cannot hold for risk neutrality.
} 


\subsection{The Two-Periods Case}

We now solve the full model, using backward induction. We will first use Bayes' rule to determine the probability $\operatorname{Pr}\{s=H\}$ that a good interim signal occurs, and the probabilities $\operatorname{Pr}\left\{Y=Y_{H} \mid s=H\right\}$ and $\operatorname{Pr}\left\{Y=Y_{H} \mid s=L\right\}$ that the yield is high after a good or bad signal. We can then determine the possible prices $P_{1} \in\left\{P_{L}, P_{H}\right\}$ on the asset market at date $t=1$, depending on whether the signal was good $(s=H)$ or bad $(s=L)$. We then proceed to period 0 . The initial price $P_{0}$ will then depend on the expected intermediate prices $P_{H}$ and $P_{L}$.

The ex ante probability that a positive signal $s=H$ occurs is

$$
\begin{aligned}
\operatorname{Pr}\{s=H\} & =q \operatorname{Pr}\left\{s=H \mid Y=Y_{H}\right\} \\
& +(1-q) \operatorname{Pr}\left\{s=H \mid Y=Y_{L}\right\}=\frac{1+(2 q-1) \theta}{2} .
\end{aligned}
$$

After a positive signal $s=H$, Bayes' rule can be used to receive the probability that the return will be high,

$$
\begin{aligned}
\operatorname{Pr}\left\{Y=Y_{H} \mid s=H\right\} & =\frac{\operatorname{Pr}\left\{s=H \mid Y=Y_{H}\right\} \cdot \operatorname{Pr}\left\{Y=Y_{H}\right\}}{\operatorname{Pr}\{s=H\}} \\
& =q \frac{1+\theta}{1+\theta(2 q-1)} .
\end{aligned}
$$

For $\theta=0$, we get $\operatorname{Pr}\left\{Y=Y_{H} \mid s=H\right\}=q$; the signal contains no information. For $\theta=1$, we receive $\operatorname{Pr}\left\{Y=Y_{H} \mid s=H\right\}=1$. Along the same line,

$$
\begin{aligned}
\operatorname{Pr}\left\{Y=Y_{H} \mid s=L\right\} & =\frac{\operatorname{Pr}\left\{s=L \mid Y=Y_{H}\right\} \cdot \operatorname{Pr}\left\{Y=Y_{H}\right\}}{\operatorname{Pr}\{s=L\}} \\
& =q \frac{1-\theta}{1-\theta(2 q-1)} .
\end{aligned}
$$

We can now calculate the prices $P_{1}$ at date $t=1$, depending on whether the public signal is positive or negative. If it is positive, the probability of success increases to $\operatorname{Pr}\left\{Y=Y_{H} \mid s=H\right\}$, which we can substitute into (2) and get $P_{H} \equiv P_{1}(s=H)$, the price of the security after the high signal. For a negative signal, we must substitute $\operatorname{Pr}\left\{Y=Y_{H} \mid s=L\right\}$ into (2) and receive $P_{L} \equiv P_{1}(s=L)$. As a consequence, depending on the signal, the price of the security moves up or down. After positive information, the price jumps up. These potential price movements determine the risk that early investors must bear. Again using (2), we find that the price at date $t=0$ will be

$$
P_{0}=\frac{\operatorname{Pr}\{s=H\} P_{H} e^{-\rho P_{H}}+\operatorname{Pr}\{s=L\} P_{L} e^{-\rho P_{L}}}{\operatorname{Pr}\{s=H\} e^{-\rho P_{H}}+\operatorname{Pr}\{s=L\} e^{-\rho P_{L}}} .
$$


Hence, using backward induction, and using the probabilities of upward and downward movements, one can recursively establish the prices at each date. $P_{0}$ is then the issue price at date 0 . The initial owner will try and choose a disclosure policy $\theta$ such that $P_{0}$ is maximized.

Consider a numerical example with $Y_{H}=1, Y_{L}=0, q=50 \%, \rho=2$, and $\theta=25 \%$. The same numbers will be used in all graphical illustrations. We obtain $\operatorname{Pr}\{s=H\}=50 \%, \operatorname{Pr}\left\{Y=Y_{H} \mid s=H\right\}=62.5 \%$, and $\operatorname{Pr}\{Y=$ $\left.Y_{H} \mid s=L\right\}=37.5 \%$. Using backward induction, one can calculate the price after a good signal as $P_{H}=0.184$, the price after a bad signal as $P_{L}=$ 0.075 , and the initial price as $P_{0}=0.124$. According to (3), risk neutral probabilities are $44.6 \%$ for a good signal, $18.4 \%$ for a good outcome after a good signal, and $7.5 \%$ for a good outcome after a bad signal. Due to the high degree of risk aversion, risk neutral probabilities differ substantially from actual probabilities. Now there is an alternative way to calculate the initial price, $(44.6 \% \cdot 18.4 \%+(1-44.6 \%) \cdot 7.5 \%) \cdot 1=0.124=P_{0}$. No arbitrage is possible, the standard instrumentarium of arbitrage pricing can be used.

No what is the degree of disclosure $\theta$ that maximizes the issue price $P_{0}$ ? Unlike Ross (1989), we do not find a general resolution irrelevance theorem; however we get resolution irrelevance at the extreme points $\theta=0$ (no disclosure) and $\theta=1$ (perfect disclosure).

Lemma 2 (Resolution Irrelevance at the Extremes) The issue price is the same for zero disclosure and for full disclosure, $P_{0}(\theta=0)=P_{0}(\theta=1)$.

The intuition for this lemma is straightforward. If the interim signal is perfect, $\theta=1$, late investors will perfectly know the final outcome. Consequently, prices will be either $P_{H}=Y_{H}$ or $P_{L}=Y_{L}$. The probability of a high signal will be $q$, that of a bad signal will be $1-q$. Hence, all risk is borne by the early investors. If the interim signal carries no information, $\theta=0$, then nothing is learned by investors before the market in $t=1$, and $P_{H}=P_{L}=P_{0}$. Hence, all risk is borne by the late investors. In both cases, one cohort bears the complete risk, the other just uses the shares as a risk-free investment. "Swapping" cohorts does not influence the initial price $P_{0}{ }^{6}$

Full disclosure and no disclosure yields the same initial price $P_{0}$. But what happens in between? In figure 2, the function $P_{0}(\theta)$ is plotted for two different parameter constellations. In the left graphic, parameters are $Y_{H}=1, Y_{L}=$ $0, \rho=2, q=50 \%$. In the right graphic, parameters are the same, only

\footnotetext{
${ }^{6}$ Note that this result depends crucially on the assumption that risk aversion and the number of investors are the same in both cohorts. Otherwise, the price would be higher if risk were shifted to the less risk averse cohort, or to the larger cohort.
} 
Figure 2: Effect of Disclosure Policy $\theta$ on the Initial Price $P_{0}$
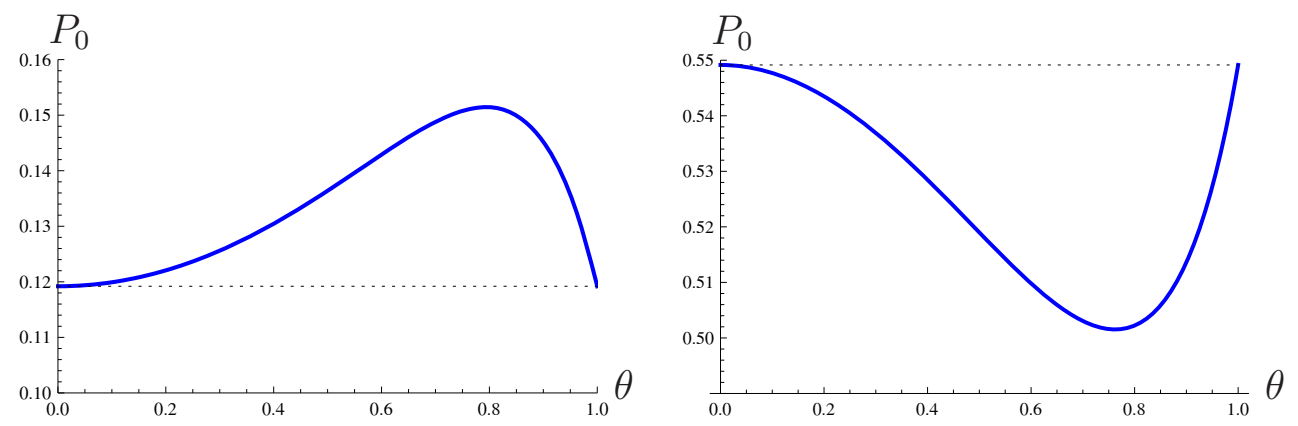

$q=90 \%$. Just from looking at these examples, we get a couple of results. First, there is no resolution irrelevancy in general. Both pictures document the fact that $P_{0}(\theta=0)=P_{0}(\theta=1)$, but in between the functions are nonconstant. Second, there can be an interior maximum (left picture). This would imply that the initial owner would choose to release some information to the market, but only vague information. Third, it is also possible that partial information is suboptimal (right picture). In this case, the initial owner would be indifferent between no disclosure $(\theta=0)$ and full disclosure $(\theta=1)$, but avoid the release of imprecise interim information.

The most important question is now under which conditions an entrepreneur chooses to implement a partial disclosure strategy, and when he prefers $\theta=0$ or $\theta=1$ (zero or full disclosure). Before answering this question, let us simplify the problem by setting $Y_{L} \equiv 0$ and $Y_{H} \equiv 1$. The following lemma tells us that we do not lose any generality.

Lemma 3 (Symmetry Results) The following two statements hold true,

$$
\begin{aligned}
P_{0}\left(Y_{H}, Y_{L}, \rho, q, \theta\right) & =P_{0}\left(Y_{H}-Y_{L}, 0, \rho, q, \theta\right)+Y_{L} \quad \text { and } \\
P_{0}\left(Y_{H}, 0, \rho, q, \theta\right) & =Y_{H} P_{0}\left(1,0, \rho Y_{H}, q, \theta\right) .
\end{aligned}
$$

The first statements tells us that if we increase both $Y_{H}$ and $Y_{L}$ by the same amount, the market price increase by exactly this amount. As a consequence, without loss of generality we can consider $P_{0}(\Delta Y, 0, \rho, q, \theta)$ instead of $P_{0}\left(Y_{H}, Y_{L}, \rho, q, \theta\right)$, with $\Delta Y=Y_{H}-Y_{L}$. The second statements tells us the multiplying $Y_{H}$ with some constant has the same effect on market prices as multiplying $\rho$ with the same constant and multiplying the price with the same constant. As a consequence, we can consider $P_{0}(1,0, \rho \Delta Y, q, \theta)$ instead of $P_{0}(\Delta Y, 0, \rho, q, \theta)$. Without loss of generality, we can even set $\Delta Y \equiv 1$, bearing in mind that an increase in variation $\Delta Y$ has the same effect as an increase in risk aversion $\rho$. Now, only two exogenous parameters are left in 
the model, $\rho=\rho \Delta Y$ and $q$. The following proposition states their influence on the optimal disclosure policy.

Proposition 1 (Optimal Disclosure Policy) The function $P_{0}(\theta)$ has an interior maximum $\theta^{*}$ if

$$
q<\frac{e^{\rho}\left(e^{\rho}-\rho-1\right)}{\left(e^{\rho}-1\right)^{2}}
$$

Because the function $P_{0}(\theta)$ is not constant, if it does not have an inner maximum, it must exhibit an inner minimum. Hence, sharing financial risk between cohorts can increase the market valuation $P_{0}$, but it does not have to. Intertemporal risk sharing is thus fundamentally different from static risk sharing. The aggregate risk premium may be minimized if all risk is shifted to one cohort.

The proposition is illustrated by figure 3. For large $q$ or for low $\rho$, we end up in the gray region where the initial owner chooses zero (or full) disclosure. For small $q$ or for high $\rho$, the initial owner chooses noisy disclosure in the white region. The black curve marks critical parameter combinations, as defined by (5). Let us give some intuition why there may be an interior optimum in the first place, and how $q$ and $\rho$ influence this property.

Figure 3: Optimal Disclosure Policy

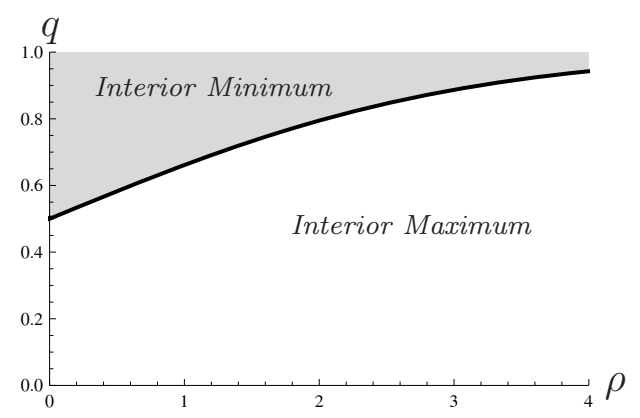

Parameters are $Y_{H}=1$ and $Y_{L}=0$. However, because of lemma 3, $\rho$ and $q$ represent the complete parameter space without loss of generality. The black curve gives condition (5), so that above this curve, the function $P_{0}(\theta)$ has an interior minimum; below the curve, $P_{0}(\theta)$ has an interior maximum.

If $q$ is low or $\rho$ is high, the initial price $P_{0}$ lies relatively low in the range $\left[Y_{L} ; Y_{H}\right]$. From the fourth point of lemma 1, we know that the initial owner benefits from value increases for the investors only up to some point. Therefore, the initial owner designs the disclosure policy to avoid large upward price jumps; he chooses partial disclosure, $0<\theta<1$. As a result, risk is distributed evenly between cohorts. 
The intuition for the possibility of an interior minimum is slightly more involved. Because the signal $s$ is garbled for $0<\theta<1$, it is always misleading with positive probability. The signal can be negative although the final yield is high. Especially for a relatively high initial price $P_{0}$ (hence, for large $q$ or low $\rho$ ), a negative signal can entail a steep price drop, with the possibility of a rebound in the second period, a rebound that overcompensates the initial price drop. At this point, remember that the initial owner does not benefit from large price increases. Consequently, he will avoid the price drop and rebound altogether, for example by setting $\theta=0$. This argument explains why the function $P_{0}(\theta)$ has an interior maximum for high $\rho$ or low $q$, and it exhibits a minimum in the opposite case.

We have assumed that the initial owner can choose $\theta$ within the interval $[0 ; 1]$. In reality, there may be reasons why this interval is trimmed. First, information may leak out of the firm at the interim date. Investors will then aggregate this information and the disclosed signal precision $\theta$ to a new signal. This signal will then have some minimum precision $\theta_{\min }$, equal to the quality of the leaking information. If the price function has an interior minimum (see figure 3), the maximum is reached for full disclosure, $\theta^{*}=1$. Second, the final outcome $Y$ may not be predictable with certainty, entailing a maximum precision $\theta_{\max }$. The precision can be reduced by additional garbling, but it cannot be increased. Then if the price function has an interior minimum, the maximum is reached for zero disclosure, $\theta^{*}=0$. These insights may help explain why firms stopped to publish earnings forecasts in the financial crisis. Our model implies that, if the future becomes less predictable and the maximum precision $\theta_{\max }$ is reduced, firms switch to zero disclosure (instead of just reducing disclosure).

Figure 4: Optimal Level of Disclosure

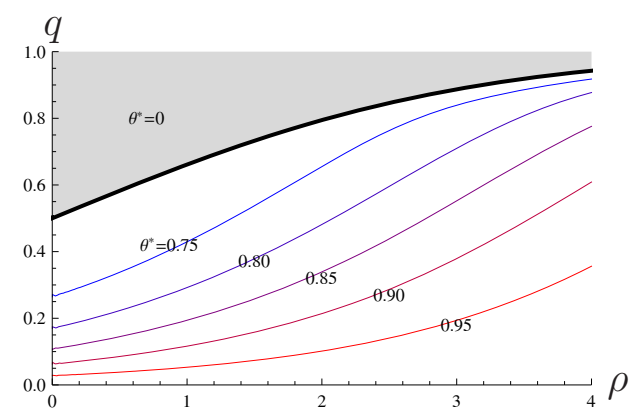

Parameters are $Y_{H}=1$ and $Y_{L}=0$, as before.

Figure 4 shows the optimal level of disclosure for varying $q$ and $\rho$. Again, we have set $Y_{L}=0$ and $Y_{H}=1$ without loss of generality (see lemma 3 ). There are a number of properties to be seen. First, in the gray region, either $\theta=0$ or $\theta=1$ is optimal. In the white region, the optimal $\theta$ increases in 
$\rho$ and decreases in $q$. Consequently, assuming that the initial owner opts for $\theta=0$ when indifferent (in the gray region), we see that the optimal degree of disclosure increases in $\rho$ and decreases in $q$. Second, the optimal level of disclosure approaches 1 as $q$ goes to zero, or $\rho$ becomes extremely large. Third, at the implicit function defined by (5), there is a discontinuity in the optimal $\theta$. From a strictly positive $\theta$ in the white region, $\theta$ drops to zero in the gray region. Indeed, the minimal possible $\theta$ that can be obtained as an interior optimum is $\theta=1 / \sqrt{2} \approx 0.71$, at the point $(q=0.5, \rho \approx 0)$. Hence, the initial owner never finds it optimal to disclose very vague information. If he chooses to disclose at all, there is a minimum level of precision with $\theta=1 / \sqrt{2}$.

\section{Applications and Hypotheses}

In this section, we apply the model to a number of questions, and derive testable hypotheses. Some applications are immediate consequences of the model, for others we have to modify the assumptions.

\subsection{The Shape of the Distribution}

Stochastic Moments. We have seen that the optimal disclosure policy depends on the success probability $q$ and risk aversion $\rho$, where $\rho$ is short for $\rho\left(Y_{H}-Y_{L}\right)$ because we have set $Y_{H}=1$ and $Y_{L}=0$ without loss of generality. So, both parameters $q$ and $\rho$ are connected to the shape of the distribution. Thus, for easier interpretation, let us rewrite results in dependence from stochastic moments. First of all, the first statement of lemma 3 states that increasing both $Y_{H}$ and $Y_{L}$ by the same amount $c$ only shifts the complete function $P_{0}(\theta)$ upwards by $c$. The shape of the function does not chance, hence the optimal $\theta$ remains constant. As a consequence, the optimal disclosure policy does not depend on the mean of the yield distribution.

Second, $\rho$ appears only in the factor $\rho\left(Y_{H}-Y_{L}\right)$. Instead of setting $Y_{H}=1$ and $Y_{L}=0$, let us set $\rho=1$ and $Y_{L}=0$ without loss of generality, being left with the two parameters $Y_{H}$ and $q$. Now the second stochastic moment $\sigma$ and the third moment $\nu$ of the distribution are functions of $Y_{H}$ and $\rho$,

$$
\begin{aligned}
& \mu=q Y_{H}+(1-q) Y_{0}=q Y_{H}, \\
& \sigma=\sqrt{q\left(Y_{H}-\mu\right)^{2}+(1-q) \mu^{2}}, \\
& \nu=\frac{q\left(Y_{H}-\mu\right)^{3}-(1-q) \mu^{3}}{\sigma^{3 / 2}} .
\end{aligned}
$$


Reversely, one can write $q$ and $Y_{H}$ as implicit functions of the standard deviation $\sigma$ and skewness $\nu$,

$$
\begin{aligned}
Y_{H} & =\sigma \sqrt{4+\nu^{2}} \\
q & =\frac{1}{2}-\frac{\nu}{2 \sqrt{4+\nu^{2}}} .
\end{aligned}
$$

We can now plot the optimal level of disclosure depending on the standard deviation $\sigma$ and skewness $\nu$ (figure 5), and get the following remark.

Remark 1 The mean of the yield distribution does not influence the optimal disclosure policy. Both higher standard deviation $\sigma$ and a higher skewness imply a higher optimal level of disclosure.

Figure 5: Optimal Disclosure Policy

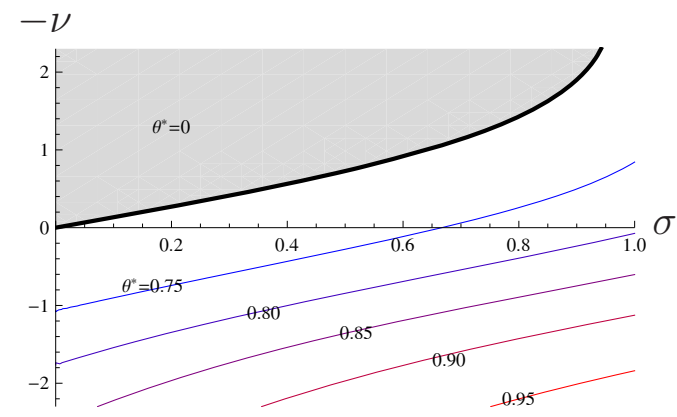

Parameters are $Y_{H}=1$ and $Y_{L}=0$, as before. For comparability with figure 4 , we use $-\nu$ instead of $\nu$ as the ordinate.

Note that $\sigma$ and $\nu$ are stochastic moments of the yield $Y$, not of the probability distribution of prices $P_{1}$ (which is endogenous). Arguably, both risk and skewness are higher in innovative industrial sectors. Projects are likely to fail, but if they do not fail, they can deliver high returns, the distribution is typically skewed to the right (positive skewness). Consequently, the above remark implies that a high level of disclosure. For more traditional industries, risk is relatively small and the distribution is skewed more to the left. Consequently, the remark predicts less disclosure, or no disclosure at all.

Autoregressive Effects. In our model, the distribution of risk over time is endogenous. We can thus ask whether the implied patterns are consistent with stylized facts. For example, after a price drop of an asset, the volatility of price movements typically increases. In order to apply our model to this question, let us assume that before period 0, there is a piece of information 
that defines $q$; the rest of the model processes as before. Possibly, the firm can react to a downward movement (low $q$ ) by disclosing more information, thus moving risk from the far future (second period in the original timing) do the near future (first period). If this is the case, we would observe exactly the autoregressive pattern of the stylized fact.

Now looking at figure 4, this is exactly the case. Assume that the initial owner decides upon disclosure after finding out that $q$ is high (hence, after an upward price movement). If $q$ is high enough to land in the gray region, there will be zero disclosure. Hence, there will be no price movements in period 1, and a large movement in period 2. If, on the other hand, $q$ is in the white region in figure 4, the lower $q$ is, the higher the precision of disclosure. Expected price movements will be large in the first period, and smaller in the second. In line with the stylized facts, our model suggests that volatility should be higher after a price drop, and small after a price increase.

\subsection{Concentration of Ownership}

Up to now, shares were assumed to be evenly distributed between investors. Now assume that, for some exogenous reason, only a fraction $n<1$ of investors can buy shares. The remaining fraction $1-n$ has no influence on asset prices. Thus $1 / n$ stands for the concentration of ownership. In the formal analysis, marginal utility from buying another share must still be zero, but each investor now holds more shares $1 / n$. Now $\partial u(P, \alpha) /\left.\partial \alpha\right|_{\alpha=1 / n}$ implies

$$
P=\frac{q Y_{H} e^{-\rho / n Y_{H}}+(1-q) Y_{L} e^{-\rho / n Y_{L}}}{q e^{-\rho / n Y_{H}}+(1-q) e^{-\rho / n Y_{L}}} .
$$

Hence, $\rho$ measures both risk aversion and ownership concentration. Therefore, any result concerning risk aversion becomes a statement on ownership concentration. For example, for low ownership concentration, zero disclosure may be optimal. The more concentrated ownership is, the higher the optimal level of disclosure.

Possibly, ownership concentration can change over time. For example, the firm may first be held by a small number of large investors (such as investment banks) who then gradually sell, such that assets are widely held in the end. In this case, ownership concentration decreases over time, which corresponds to decreasing risk aversion over time, $\rho_{2}<\rho_{1}$. This has a number of consequences. First, lemma 2 no longer holds, $P_{0}(\theta=0)>P_{0}(\theta=1)$. The argument is straightforward. Because ownership concentration is smaller in the second period, the risk premium for late investors is smaller. Therefore, c. p., shifting risk to late investors reduces the aggregate risk premium, and increases the 
initial price $P_{0}$. Now the fact that a low level of disclosure $\theta$ reduces risk for early investors and increases risk for late investors completes the argument. With the same procedure as in the proof of proposition 1, we arrive at the following remark.

Remark 2 The function $P_{0}(\theta)$ has an interior maximum if

$$
q<\frac{e^{\rho_{2}}\left(e^{\rho_{2}}-\rho_{1}-1\right)}{\left(e^{\rho_{2}}-1\right)^{2}} .
$$

For $\rho_{2}<\rho_{1}$, the critical $q$ is smaller than that for identical ownership concentration in both periods. The range of parameters where zero disclosure is optimal becomes larger. Summing up, if ownership concentration decreases over time, the optimal degree of disclosure decreases. For $\rho_{2}>\rho_{1}$, a reverse argument applies.

\subsection{Market Liquidity}

In the model, all early investors have to sell at date 1, implying that the complete market is turned over in one period. By assuming that only a fraction of investors needs to sell at date 1 , we can reduce the turnover (liquidity). Such a reduced liquidity will have a couple of consequences. Clearly, because some investors hold the asset for both periods, the importance of intertemporal risk sharing will decrease, and the impact of disclosure levels on share prices will decline. The optimal level of disclosure itself may also change, but the direction in unclear a priori.

Let us now assume that, at date 1 , only a fraction $\lambda \leq 1$ must leave the market (potentially due to a stochastic liquidity shock), but another mass $\lambda$ enters the market. Hence, the aggregate mass of investors is 1 at each date. Now $\lambda$ is a measure for market turnover, or liquidity. For $\lambda=0$, there is no interim trading, and disclosure policy is irrelevant. For $\lambda=1$, the complete volume is traded at $t=1$, and we have our original model.

Prices are determined only by future payoff expectations, they are independent of whether investors have held the asset in the preceding period or not. Consequently, interim prices at date $t=1$ are independent of liquidity $\lambda . P_{H}$ and $P_{L}$ are not influenced by whether an asset has been held or traded, hence $P_{H}$ and $P_{L}$ are independent of $\lambda$. However, the initial price $P_{0}$ will be influenced by $\lambda$. When making investment decisions, investors take into account that they will hold the asset until $t=2$ with probability $1-\lambda$, and get payoffs of $Y_{H}$ and $Y_{L}$ with the according probabilities, or only hold the asset until $t=1$ with 
probability $\lambda$, and get payoffs of $P_{H}$ and $P_{L}$ with the according probabilities. Expected utility of buying $\alpha$ units of the asset at date $t=0$ yields

$$
\begin{aligned}
u\left(P_{0}, \alpha\right) & =\lambda\left(\operatorname{Pr}\{s=H\} u\left[w+\alpha\left(P_{H}-P_{0}\right)\right]\right. \\
& \left.+(1-\operatorname{Pr}\{s=H\}) u\left[w+\alpha\left(P_{L}-P_{0}\right)\right]\right) \\
& +(1-\lambda)\left(q u\left[w+\alpha\left(Y_{H}-P_{0}\right)\right]+(1-q) u\left[w+\alpha\left(Y_{L}-P_{0}\right)\right]\right) .
\end{aligned}
$$

In the competitive market equilibrium, $\partial u\left(P_{0}, \alpha\right) / \partial \alpha=0$ must hold, and the market must clear, $\alpha=1$. This again yields an implicit function $P_{0}(\theta)$, which may exhibit an interior maximum or minimum. We have already discussed the extreme case of a perfectly liquid market, $\lambda=1$. For illustration, consider the other extreme of an illiquid market, $\lambda \rightarrow 0 .^{7}$

The left part of figure 6 shows the optimal levels of disclosure for $\lambda \rightarrow 0$. For comparison, the right part shows the optimal levels both for $\lambda \rightarrow 0$ (dashed) and $\lambda=1$ (solid, as in figure 4). Two properties are important. First, the function $P_{0}(\theta)$ has an interior minimum for zero liquidity $(\lambda=0)$ whenever it has an interior minimum for full liquidity $(\lambda=1)$. Hence, the answer to the question whether partial disclosure is optimal does not depend on the degree of liquidity. Second, if partial disclosure is optimal, the optimal precision $\theta^{*}$ depends positively on liquidity, $d \theta^{*} / d \lambda>0$.

Remark 3 The question whether partial disclosure is optimal is independent of the degree liquidity $\lambda$. If partial disclosure is optimal, the optimal level $\theta^{*}$ is larger for higher degrees of liquidity, $d \theta^{*} / d \lambda>0$.

\section{The Investors' Interests - Welfare}

The initial owner of the firm aims at maximizing the issue price $P_{0}$. Up to now, we have hence implicitly taken the initial owner's perspective. However, the investors may not be indifferent with respect to the allocation of risk over time. They are, of course, indifferent with respect to buying one more marginal share at the given price, but this does not imply that they do not earn any rents. If information were perfect and the final payoff $Y$ were known, an investor's demand function would be flat, hence his rent would be zero. With uncertainty, demand for shares is elastic, and thus rents will be positive. The

\footnotetext{
${ }^{7}$ The boundary case with $\lambda=0$ cannot be discussed, because no shares are traded and disclosure is thus irrelevant. However, in the limit $\lambda \rightarrow 0$, the optimal disclosure policy converges (although the impact of disclosure becomes vanishingly small).
} 
Figure 6: Optimal Disclosure Policy in an Illiquid Market
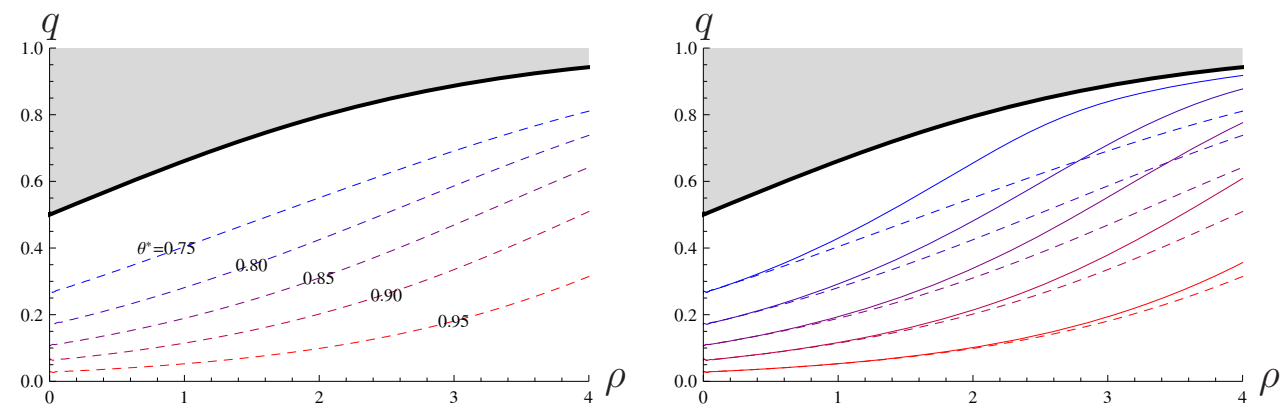

The left picture shows the optimal levels of disclosure $\theta^{*}$ (as iso-optimal-degree-of-disclosure curves) for the limiting case of zero liquidity, $\lambda \rightarrow 0$. Now compare this figure to figure 4 (where all early investors had to sell at date $t=1$, hence $\lambda=1$ ). The two pictures looks similar at first glance; the border between zero disclosure and partial disclosure is identical, but the iso- $\theta^{*}$-curves are shifted towards higher $\rho$ (or, equivalently, smaller $q$ ). This becomes visible by superimposing the two figures (right picture, with dashed curves for $\lambda=0$ and solid curves for $\lambda=1$ ). For small degrees of risk aversion, the curves are nearly identical, but for larger $\rho$, the difference becomes more pronounced. In comparison, the optimal $\theta$ is higher for larger liquidity $\lambda$.

higher the risk for a cohort, the higher the rents that this cohort will earn. As a consequence, from an ex ante perspective, each cohort will want to bear as much risk as possible. Early investors would like to implement full disclosure $(\theta=1)$, which would move the complete risk to themselves. Late investors prefer $\theta=0$.

Lemma 4 (Extreme Diversion of Interests) From an ex ante perspective, early investors find $\theta=1$ (full disclosure) optimal, the second cohort prefers $\theta=0$ (zero disclosure). From an ex interim perspective, preference orderings are reversed.

Investors like risk ex ante because it enables them to pay a low price for the issue. Consequently, their attitude changes as soon as they have bought the issue: early investors will prefer not to have any information revealed while they own the shares. The same holds true for late investors.

The lemma suggests that, if disclosure standards were determined in a political process, the result would heavily be influenced by the timing of the decision (and by the proportion between cohorts of investors). Each cohort would lobby towards vague disclosure once they held shares; beforehand, they would argue they want to have access to information as soon as it is available. ${ }^{8}$

\footnotetext{
${ }^{8}$ Note that these preferences refer to complete cohorts of investors. Individually, each investor wants as much information as possible before trading. Cohort-wise, investors want to be uninformed before trading.
} 
Figure 7: The Investors' Expected Utility
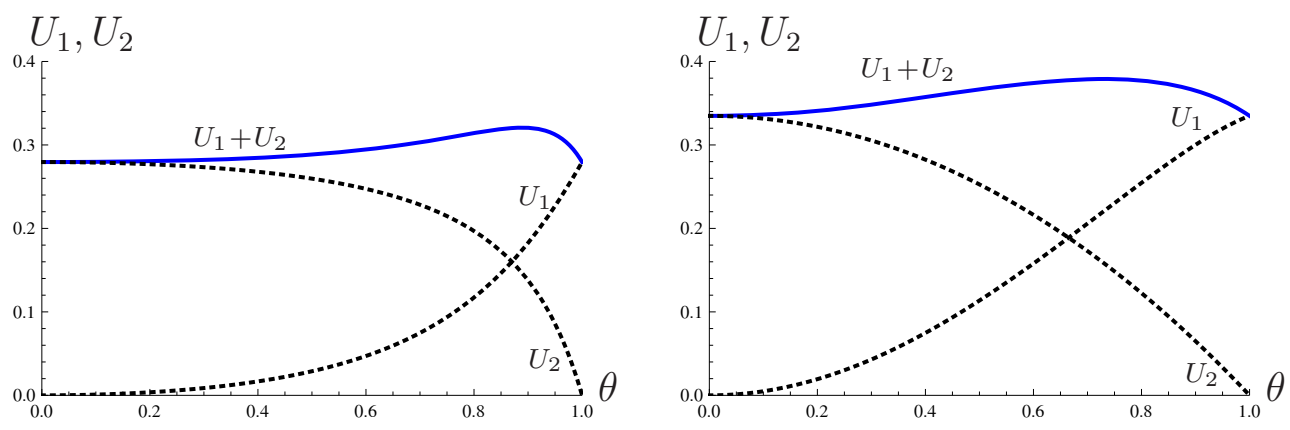

Like in figure $2, q=50 \%$ in the left picture, and $q=90 \%$ in the right.

Let us define (investor) welfare as the sum of investors' utilities, $W(\theta)=$ $U_{1}(\theta)+U_{2}(\theta) .{ }^{9}$ Figure 7 shows the expected utilities of each group of investors as dotted lines for two numerical examples. Lemma 4 is confirmed: $U_{1}$ increases with $\theta$, whereas $U_{2}$ decreases. We see that, in analogy to lemma 2, a welfaremaximizing regulator is also indifferent between zero and full disclosure, $W(\theta=$ $0)=W(\theta=1)$. Furthermore, the welfare function $W(\theta)$ exhibits an interior maximum $\hat{\theta}$ even for parameter constellations where the price function $P_{0}(\theta)$ had an interior minimum. This observation is general, as shown in the following proposition.

Proposition 2 (Welfare-Optimal Disclosure) Welfare is always maximized with partial disclosure, $\hat{\theta} \in(0 ; 1)$

The reason why there is always an interior maximum at an interior $\hat{\theta}$ differs slightly from the explanation for an interior maximum of $P_{0}(\theta)$. With a grain of salt, a single cohort's ex ante utility increases with the amount of risk it takes. But due to risk aversion, the marginal utility with respect to taking more risk is decreasing; it can even become negative. This implies that, by sharing risk between the two cohorts, the aggregate rent of investors is maximized. A formal discussion is in the proof of proposition 2 in the appendix.

Figure 8 shows the welfare-optimal levels $\hat{\theta}$ of disclosure. Parameters are $Y_{H}=$ 1 and $Y_{L}=0$, but remember that the figure is general because $Y_{H}=1$ and $Y_{L}=0$ without loss of generality due to lemma 3. Therefore, in comparison

\footnotetext{
${ }^{9}$ There are three reasons to do so. First, our result that the welfare-optimal level of disclosure $\hat{\theta}$ exceeds the level $\theta^{*}$ preferred by the initial owner will hold true if some utility of the owner is taken into account. Second, this way, we do not need to make any assumptions about the initial owner's utility function. Finally, the initial owner is negligible in comparison to a continuum of investors.
} 
Figure 8: Welfare-optimal Disclosure Policy
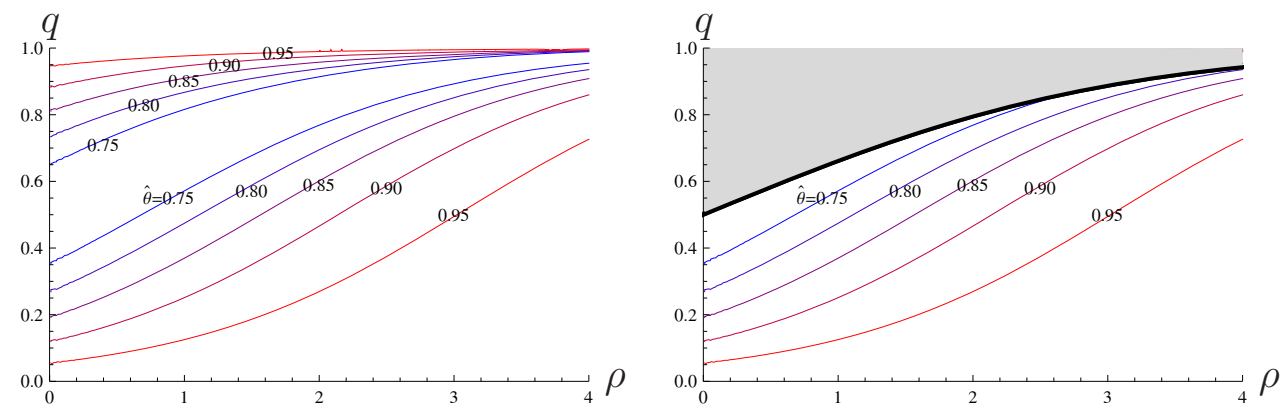

In the left picture, the curves show the welfare-optimal $\hat{\theta}$, depending on parameters $\rho$ and $q$. Partial disclosure is always welfare-optimal. In the right picture, the initial owner chooses zero disclosure in the gray region although partial disclosure would be welfare-optimal. Furthermore, an eyeball comparison between the $\hat{\theta}$ in this figure and the $\theta^{*}$ from figure 4 shows that $\hat{\theta}>\theta^{*}$ for all combinations of $q$ and $\rho$; the welfare-optimal level of disclosure always exceeds the level preferred by the initial owner.

with figure 4, we find three properties. First, the initial owner may choose zero disclosure although partial disclosure is welfare-optimal. Second, even if the initial owner prefers partial disclosure, the welfare-optimal level $\hat{\theta}$ is always higher. Third, full disclosure is never welfare-optimal (except for the limiting case of $q \rightarrow 0$ ).

Remark 4 The welfare-optimal disclosure level $\hat{\theta}$ exceeds the laissez-faire level $\theta^{*}$.

This remark has some implications for a potential regulation of disclosure. Independent of external parameters, there is always scope for regulation, because the laissez-faire level of disclosure $\theta^{*}$ is below the welfare optimum. Furthermore, if the regulator imposes minimum disclosure standards, there should not be as high as possible. More information is not better. Finally, the optimal disclosure standard is not a fixed number, but depends on exogenous parameters. More risky firms should have higher disclosure standards, and so should more innovative firms, and more closely held firms.

\section{Conclusion}

Introducing liquidity concerns into a disclosure model with risk averse investors, we have found a rich set of implications, even in the complete absence of asymmetric information. The market's appreciation for large upward value 
increases is limited, hence a firm should design its disclosure policy to avoid large upward jumps. Therefore, if the upward potential of a stock is large, the firm should release information gradually, and there is an optimal precision of the disclosure information. In the opposite case, if the cash flow distribution exhibits negative skewness, i. e. if there is a low probability of a large downside risk, a gradual release of information reduces share prices and zero disclosure maximizes the share price instead. The prospect of intertemporal risk sharing thus increases share prices in some cases, but not all.

This general insight can be applied in various ways. For example, consider the stochastic moments of the underlying asset's cash flow. In a market equilibrium, a higher mean will increase the initial price, but leave the upward potential for investors unchanged. Consequently, we find that the mean does not influence optimal disclosure policy. If investors are risk averse, a large standard deviation increases the risk premium, and hence depresses the initial price. Consequently, the upward potential increases, rendering partial disclosure optimal. Finally, a positive skewness implies that price increases are unlikely but can be large, whereas price decreases are likely but are more limited in size. Hence, for large positive skewness, partial disclosure is optimal. On the other hand for large negative skewness, if there is no disclosure, the market value of the firm is maximized.

In many financial transactions, ownership concentration of stocks changes abruptly. For example, in an IPO, concentration decreases, with consequences on optimal intertemporal risk allocation, and hence also on disclosure policy. Because the ownership base broadens under an IPO, the later cohort of investors can easier bear the financial risk, hence the risk premium will be relatively low. As a consequence, optimal disclosure will be relatively noisy. Also the degree of liquidity of an asset influences the disclosure policy. With less trading, the intertemporal allocation of risk plays less of a role. At the same time, the optimal degree of disclosure decreases.

Importantly, the welfare-optimal degree of disclosure weakly exceeds the pricemaximizing degree, with two consequences. First, maximal disclosure does not need to be optimal. This result is not surprising in our setting, as full disclosure would imply zero intertemporal risk sharing. Second, disclosure should be regulated; firms should be forced to disclose more than they want. As a consequence, disclosure regulation needs to be fine-tuned, and it can differ between firms or assets with different ownership structures, different risk structures, different payoff profiles, and different degree of liquidity.

In the light of the recent financial crisis, the academic and policy debate about information disclosure and the role of transparency especially in financial firms is likely to remain controversial. Our paper adds the aspects of liquidity concerns and intertemporal risk sharing to this debate and delivers some new 
insights. The model implies that if the economic environment becomes less predictable in the sense that firms get less precise signals, then it is optimal for firms to switch to zero disclosure instead of just reducing disclosure. This provides a rationale for the observation that during the recent financial crises many firms stopped providing earnings guidance.

\section{A Appendix}

Proof of Lemma 1: Taking derivatives, we obtain

$$
\begin{aligned}
\frac{d P}{d q} & =e^{\rho\left(Y_{H}+Y_{L}\right)} \frac{\left(Y_{H}-Y_{L}\right)}{\left(q e^{\rho Y_{L}}+(1-q) e^{\rho Y_{H}}\right)^{2}}>0, \\
\frac{d P}{d \rho} & =-q(1-q) e^{\rho\left(Y_{H}+Y_{L}\right)} \frac{\left(Y_{H}-Y_{L}\right)^{2}}{\left(q e^{\rho Y_{L}}+(1-q) e^{\rho Y_{H}}\right)^{2}}<0, \\
\frac{d P}{d Y_{L}} & =(1-q) e^{\rho Y_{H}} \frac{q e^{\rho Y_{L}}\left(1+\rho\left(Y_{H}-Y_{L}\right)\right)+(1-q) e^{\rho Y_{H}}}{\left(q e^{\rho Y_{L}}+(1-q) e^{\rho Y_{H}}\right)^{2}}>0, \\
\frac{d P}{d Y_{H}} & =q e^{\rho Y_{L}} \frac{q e^{\rho Y_{L}}+(1-q) e^{\rho Y_{H}}\left(1-\rho\left(Y_{H}-Y_{L}\right)\right)}{\left(q e^{\rho Y_{L}}+(1-q) e^{\rho Y_{H}}\right)^{2}} .
\end{aligned}
$$

The last term is positive if and only if $Y_{H}-Y_{L}<\left(1+\operatorname{plog}\left[e^{-1} q /(1-q)\right]\right) / \rho$, where plog $y$ is the product log, the solution of the equation $y=x e^{x}$.

The property that the $d P / d Y_{H}$ reaches a maximum at some $Y_{H}$ is not specific to exponential utility functions of investors. Consider constant relative risk aversion, $u(c)=c^{1-\rho}$, with $\rho>1$. The relative risk aversion is then $\rho>1$. In analogy to $(2)$, we then get

$$
\begin{aligned}
\left.\frac{\partial u(P, \alpha)}{\partial \alpha}\right|_{\alpha=1} & =(1-\rho) q\left(Y_{H}-P\right)\left(W+Y_{H}-P\right)^{-\rho} \\
& +(1-\rho)(1-q)\left(Y_{L}-P\right)\left(W+Y_{L}-P\right)^{-\rho} .
\end{aligned}
$$

If the market clears, this term (8) must be equal to zero. Due to risk aversion, the price $P$ cannot exceed the expected yield, $P \leq q Y_{H}+(1-q) Y_{L}$. As a consequence, $\left(Y_{H}-P\right)\left(W+Y_{H}-P\right)^{-\rho} \rightarrow 0$ as $Y_{H} \rightarrow \infty$. However, this implies that also $\left(Y_{L}-P\right)\left(W+Y_{L}-P\right)^{-\rho}$ must converge to zero for $Y_{H} \rightarrow \infty$, which is only possible if $P \rightarrow Y_{L}$. This proves that the function $P\left(Y_{H}\right)$ cannot be monotonic if the relative risk aversion $\rho$ exceeds 1 .

Proof of Lemma 2: If $\theta=0$, then $\operatorname{Pr}\{s=H\}=1 / 2, \operatorname{Pr}\left\{Y=Y_{H} \mid s=\right.$ $H\}=q$, and $\operatorname{Pr}\left\{Y=Y_{H} \mid s=L\right\}=q$. The signal contains no information, nothing can be learned. Consequently, $P_{H}=P_{L}$, and hence

$$
P_{0}=\frac{q Y_{H} e^{-\rho\left(Y_{H}-Y_{L}\right)}+(1-p) Y_{L}}{q e^{-\rho\left(Y_{H}-Y_{L}\right)}+(1-q)}
$$


as in (2). Now consider the second case, $\theta=1$. Then $\operatorname{Pr}\{s=H\}=q$, $\operatorname{Pr}\left\{Y=Y_{H} \mid s=H\right\}=1$, and $\operatorname{Pr}\left\{Y=Y_{H} \mid s=L\right\}=0$. As a result, $P_{H}=Y_{H}$ and $P_{L}=Y_{L}$, and $P_{0}$ is exactly as above. Hence, $P_{0}$ is independent from whether $\theta=0$ or $\theta=1$.

Proof of Lemma 3: The first statement is obvious. For the second statement, first look at the one-period case,

$$
P\left(c Y_{H}, 0, \rho, q, \theta\right)=\frac{q c Y_{H} e^{-\rho c Y_{H}}}{q e^{-\rho Y_{H}}+(1-q)}=c P\left(Y_{H}, 0, c \rho, q, \theta\right) .
$$

This result carries immediately through to the two-period case.

Proof of Proposition 1: We want to distinguish between the two cases of figure 2. Both have $d P_{0} /\left.d \theta\right|_{\theta=0}=0$, this can easily be shown analytically. Hence, to see whether the function increases or decreases around $\theta=0$, consider the second derivative at the origin,

$$
\left.\frac{d^{2} P_{0}}{d \theta^{2}}\right|_{\theta=0}=8 e^{\rho} q^{2}(1-q)^{2} \frac{e^{\rho}\left(2 q+e^{\rho}(1-q)-\rho-1\right)}{\left(e^{\rho}(1-q)+q\right)^{4}} .
$$

This term is positive iff (5) holds. Consequently, $P_{0}(\theta)$ increases around $\theta=0$, but $P_{0}(1)=P_{0}(0)$. Because $P_{0}(\theta)$ is differentiable, there must be an interior optimum.

Proof of Lemma 4: We first want to argue that ex ante, each cohort of investors wants to bear as much risk as possible. Look at one cohort only, and set $W=0$ without loss of generality. Furthermore, set $Y_{H}=\bar{Y}+(1-p) \epsilon$ and $Y_{L}=\bar{Y}-p \epsilon$, such that the mean is always $\bar{Y}$, and $\epsilon$ measures (lack of) information before the trade. Then, substituting (2) into (1) with $\alpha=1$ due to market clearing, we receive

$$
u=-\left((1-p) e^{\frac{p \epsilon \rho}{(1-p) e^{\epsilon \rho}+p}}+p e^{\frac{-(1-p) \epsilon \rho}{p e^{-\epsilon \rho}+(1-p)}}\right),
$$

$\bar{Y}$ drops out of the equation. The derivative with respect to $\epsilon$ is

$$
\frac{\partial u}{\partial \epsilon}=\frac{(1-p) p \epsilon \rho^{2} e^{\frac{p \epsilon \rho}{(1-p) e^{\epsilon} \rho+p}}}{(1-p) e^{\epsilon \rho}+p}
$$

which is positive for $\epsilon>0$. As a consequence, higher risk raises utility (ex ante). Now take the ex interim perspective, i. e., keep the price fixed. Then (1) with $\alpha=1$ yields

$$
u=-\left(p+(1-p) e^{\epsilon \rho}\right) e^{(P-\bar{Y})-(1-p) \epsilon} .
$$


The derivative with respect to $\epsilon$ is now

$$
\frac{\partial u}{\partial \epsilon}=\rho p(1-p)\left(1-e^{\epsilon \rho}\right) e^{(P-\bar{Y})-(1-p) \epsilon},
$$

which is negative for $\epsilon>0$. Hence, higher risk decreases utility ex interim. The argument, as it stands, applies to early and late investors. Hence ex ante, early investors find $\theta=1$ optimal; late investors like $\theta=0$ best. Ex interim, preferences are reversed.

Proof of Proposition 2: The proof is structurally similar to that of proposition 1. From figure 7, we have an example where welfare is hump-shaped in $\theta$, it reaches its optimum for some $\theta^{*} \in(0 ; 1)$. So in order to turn into a U-shaped function, $d^{2} W(\theta) / d \theta^{2}$ would have to vanish at $\theta=0$ for some parameter constellation $(\rho, q)$. However,

$$
\left.\frac{d^{2} W}{d \theta^{2}}\right|_{\theta=0}=\frac{4 q^{2}(1-q)^{2} \rho^{2} e^{\rho}}{\left(e^{\rho}(1-q)+q\right)^{4}}\left(e^{\rho}-e^{\frac{\rho q}{e^{\rho(1-q)+q}}}\left(e^{\rho}(1-q)+q\right)\right) .
$$

Some algebra shows that the last bracket is positive for $0<q<1$ and $\rho>0$, hence the whole derivative is positive.

\section{B Time Line of the Porsche Case}

July 18, 2001. The talk between Deutsche Boerse and Porsche on MDAX listing fails and decision on de-listing is due August 7. Deutsche Boerse board member Christoph Lammersdorf: "Porsche refuses to publish full quarterly earnings report and does not therefore fulfill the MDAX membership criteria. Whoever is in an index should inform it's shareholders simultaneously, regularly and fully. Quarterly earnings reports increase transparency in the capital market."

Wendelin Wiedeking, CEO of Porsche: "We do not want to enter into short-term consideration that came as a result of quarterly targets. There is a big danger that you only manage in such a way that the quarterly figures are good (...) that short-term way of thinking is not in my view a sensible way of running a business."

Press Release by Porsche: Recent experience in particular has demonstrated that quarterly reports not only lead to greater bureaucratic costs and effort but, even worse, also interfere with a company's pursuit of its long-term growth strategies. They have not contributed to greater transparency, as shown by the developments on the new market. As Porsche sees it, the main effort of quarterly reports is to increase the volatility on the stock market. We feel that quarterly reports are first and foremost a plan to drum up business for Deutsche Boerse and the banks. We would have appreciated if the Deutsche Boerse had acknowledged its true motives in this matter.

August 7, 2001. Deutsche Boerse announces that Porsche to be ejected from MDAX index, effective September 24. 
August 9, 2001. The German government may draft a law forcing companies to report results every quarter.

October 11, 2001. The German government is dropping plans for law forcing publicly traded companies to release quarterly earnings report after a disagreement within the government and amid criticism from some companies.

October 31, 2001. Porsche receives distinguished award for financial market communications from "Investor Relation Magazine."

Sources: Agence France Presse (7/18/01), AFX Europe Focus (8/7/01), Bloomberg News (7/18/01, 8/9/01, 10/11/01), Financial Times (8/7/01), Porsche Press Release (7/18/01, $10 / 31 / 01)$

\section{References}

Allen, F., S. Morris, AND H. S. Shin (2006): "Beauty Contests and Iterated Expectations in Asset Markets," Review of Financial Studies, 19(3), 719-752.

Baglioni, A., And U. Cherubini (2007): "Accounting Fraud and the Pricing of Corporate Liabilities - Structural Models with Garbling," SSRN Discussion Paper.

Biais, B., P. Bossaerts, And C. Spatt (2010): "Equilibrium Asset Pricing and Portfolio Choice under Asymmetric Information," Review of Financial Studies, 23(4), 1503-1543.

Cespa, G., And X. Vives (2008): "Dynamic Trading and Asset Prices: Keynes vs. Hayek," CSEF Working Papers \#1.

Diamond, D. W., And P. H. Dybvig (1983): "Bank Runs, Deposit Insurance, and Liquidity," Journal of Political Economy, 91(3), 401-419.

Duffie, D., And G. Manso (2007): "Information Percolation in Large Markets," American Economic Review, Papers and Proceedings, 97(2), 203-209.

Duffie, D., M. Schroder, And C. Skiadas (1996): "Recursive Valuation of Defaultable Claims and the Timing of Resolution of Uncertainty," Annals of Applied Probability, 6(4), 1075-1090.

(1997): "A Term Structure Model with Preferences for the Timing of Resolution of Uncertainty," Economic Theory, 9(1), 3-22.

Epstein, L. G., And S. M. Turnbull (1980): "Capital Asset Prices and the Temporal Resolution of Uncertainty," Journal of Finance, 35(3), 627-643.

Ross, S. A. (1989): "Information and Volatility: The No-Arbitrage Martingale Approach to Timing and Resolution Irrelevancy," Journal of Finance, 44(1), 1-17.

Sagi, J., M. Spiegel, And M. Watanabe (2009): "Dynamic Corporate Capital Stocks: Cross-sectional and Inter-temporal Stock Return Patterns," Discussion Paper.

Shin, H. S. (2006): "Disclosure Risk and Price Drift," Journal of Accounting Research, $44(2), 351-379$. 
Spiegel, M. (1998): "Stock Price Volatility in a Multiple Security Overlapping Generations Model," Review of Financial Studies, 11(2), 419-447.

Tirole, J. (1982): "On the Possibility of Speculation Under Rational Expectations," Econometrica, 50(5), 1163-1181.

Verrechia, R. E. (2001): "Essays on Disclosure," Journal of Accounting and Economics, $32(1-3), 97-180$.

Watanabe, M. (2008): "Price Volatility and Investor Behavior in an Overlapping Generations Model with Information Asymmetry," Journal of Finance, 63(1), 229-272.

Weber, T. A., And D. C. Croson (2004): "Selling less Information for more: Garbling with Benefits," Economics Letters, 83(2), 165-171. 


\section{Preprints 2010}

2010/35: Traxler C., Burhop C., Poverty and crime in 19th century Germany: A reassessment

2010/34: Dickert S., Herbig B., Glöckner A., Gansen C., Portack R., The More the Better? Effects of Training and Information Amount in Legal Judgments

2010/33: Glöckner A., Towfigh E. V., in preparation: Game Over. Empirical Support for Soccer Bets Regulation

2010/32: Glöckner A., Towfigh E. V., Geschicktes Glücksspiel. Die Sportwette als Grenzfall des Glücksspielrechts

2010/31: Hellwig M., Capital Regulation after the Crisis: Business as Usual?

2010/30: Prantl S., The Impact of Firm Entry Regulation on Long-living Entrants

forthcoming in: Small Business Economics, In Press.

2010/29: Engel C., Kurschilgen M., Fairness Ex Ante \& Ex Post - The Benefits of Renegotiation in Media Markets, Bonn, Max Planck Institute for Research on Collective Goods, 2010. Abstract Tagged BibTex XML Full Textapplication/pdf icon

2010/28: Goerg S. J., Walkowitz G., On the Prevalence of Framing Effects Across Subject-Pools in a Two- Person Cooperation Game forthcoming in: Journal of Economic Psychology, In Press.

2010/27: Chmura T., Engel C., Englerth M., Pitz T., At the Mercy of the Prisoner Next Door. Using an Experimental Measure of Selfishness as a Criminological Tool

2010/26: Weinschenk P., Skill Formation under Incomplete Information

2010/25: Brilon S., Job Assignment with Multivariate Skills

2010/24: Lang M., Wambach A., The fog of fraud - mitigating fraud by strategic ambiguity

2010/23: Albanese G., Sorge M. M., The Role of the Judiciary in the Public Decision Making Process

2010/22: Bade S., Electoral Competition with Uncertainty Averse Parties

2010/21: Leifeld P., Haunss S., A Comparison between Political Claims Analysis and Discourse Network Analysis: The Case of Software Patents in the European Union

2010/20: Burhop C., Gelman S., Transaction costs, liquidity and expected returns at the Berlin Stock Exchange, 1892-1913

2010/19: Hellwig M., Finanzkrise und Reformbedarf [The Financial Crisis and Regulatory Reform], Bonn

2010/18: Bierbrauer F., Optimal Income Taxation and Public-Goods Provision with Preference and Productivity Shocks, Bonn 2010/17: Weinschenk P., Entry and Incumbent Innovation, Bonn

2010/16: Bierbrauer F., Boyer P. C., The Pareto-Frontier in a simple Mirrleesian model of income taxation

2010/15: Grechenig K., Sekyra M., No Derivative Shareholder Suits in Europe - A Model of Percentage Limits and Collusion

2010/14: Bierbrauer F., On the optimality of optimal income taxation

2010/13: Engel C., An Experimental Contribution to the Theory of Customary (International) Law

2010/12: Leifeld P., Schneider V., Institutional communication revisited: Preferences, opportunity structures and scientic expertise in policy networks

2010/11: Grechenig K., Nicklisch A., Thöni C., Punishment despite Reasonable Doubt - A Public Goods Experiment with Uncertainty over Contributions

2010/10: Petersen N., Braucht die Rechtswissenschaft eine empirische Wende?

2010/09: Bade S., Ambiguous Act Equilibria

2010/08: Lehmann S., Volckart O., The Political Economy of Agricultural Protection: Sweden 1887

2010/07: Engel C., Dictator Games: A Meta Study 
2010/06: Engel C., Irlenbusch B., Turning the Lab into Jeremy Bentham’s Panopticon. The Effect of Punishment on Offenders and Non-Offenders

2010/05: Gropp R., Hakenes H., Schnabel I., Competition, Risk-Shifting, and Public Bail-out Policies

2010/04: Slemrod J., Traxler C., Optimal observability in a linear income tax

2010/03: Baumann, Florian; Friehe, Tim; Grechenig, Kristoffel: Switching Consumers and Product Liability: On the Optimality of Incomplete Strict Liability

2010/02: Bierbrauer F., Hellwig M., Public-Good Provision in a Large Economy

2010/01: Bierbrauer F., Incomplete contracts and excludable public goods 